\title{
Response to Perceptual Novelty in Tortoises-A Preliminary Study
}

\author{
Anna Chrzanowska \\ Institute of Psychology, PAS, ul. Jaracza 1, 00-378 Warsaw, Poland \\ E-mail: a.m.chrzanowska@gmail.com \\ Klaudia Modlinska \\ Institute of Psychology, PAS, ul. Jaracza 1, 00-378 Warsaw, Poland \\ E-mail: kmodlinska@wp.pl \\ Rafal Stryjek \\ Institute of Psychology, PAS, ul. Jaracza 1, 00-378 Warsaw, Poland \\ E-mail: rstryjek@wp.pl
}

Wojciech Pisula (Corresponding author)

Institute of Psychology, PAS, ul. Jaracza 1, 00-378 Warsaw, Poland

E-mail:wojciech.pisula@wp.pl

Received: November 11, 2015 Accepted: December 1, 2015

doi:10.5296/jbls.v7i1.8766 URL: http://dx.doi.org/10.5296/jbls.v7i1.8766

\begin{abstract}
The ways of responding to novelty have not yet been thoroughly and comprehensively researched in reptiles, and studies undertaken so far have been conducted mainly on laboratory rats. The purpose of this paper is to present results of research carried out on the land tortoises Testudo hermanni and Agrionemys horsfieldii. Current research on tortoises as study subjects indicates that while undertaking environmental exploration these animals rely, to a large extent, on their sight, which is why this study employed visual stimuli to measure the tortoises' response to novelty. In the course of the experiment, three objects were
\end{abstract}


presented: the first imitated a biologically significant stimulus, the second was biologically indifferent, while the third was variable, and therefore perceived by the animals as novel. The results obtained suggest that the biologically significant and the variable objects elicited a response which involved the animals' looking more intently at those objects than at the biologically indifferent object. It may be concluded, therefore, that tortoises have demonstrated exploratory responses which varied according to the object presented. While this study was only preliminary, the results obtained substantiate the view that tortoises may be interesting study subjects in comparative psychology.

Keywords: Exploratory activities, Response to novelty, Land tortoises, Amniotes

\section{Introduction}

Response to novelty is a behavioural element classified as exploratory activity. Research on exploratory behaviour aims to understand the process of organisms' adaptation to environmental changes. Exploration involves collecting environmental information (Pisula, 2009). It is assumed that novelty has a rewarding value for study subjects (Pisula, 2009).

Tortoises' ability to learn has long been the focus of various studies (e.g. Tinklepaugh, 1932). Researchers, however, have not, as yet, demonstrated particular interest in examining the ways tortoises deal with novelty. Studies investigating the ways of dealing with novelty have been conducted on laboratory animals, mainly rats (Pisula, 2009). Nonetheless, many researchers have presented evidence on common anatomical brain features in species belonging to different classes of amniotes (Broglio et al. 2015; Salas, Broglio and Rodríguez, 2003). For these reasons, it seems interesting to carry out comparative studies of species form various classes of animals. Such an approach may help clarify the evolution of specific higher psychological functions in amniotes.

Current research on tortoises as study subjects indicates that while undertaking environmental exploration, these animals rely, to a large extent, on their sight. Recent study suggest that Hermann's tortoises differentiate between colours of both naturally occurring flowers and artificial objects (Pellitteri-Rosa, Sacchi, Galeotti, Marchesi and Fasola, 2010). Tortoises were presented with the following colours: blue, white, red and yellow, as well as with natural flowers of different colours, e.g. bright yellow or bright purple. The animals were most successful in discerning yellow, but they were able to differentiate between the other colours as well (Pellitteri-Rosa et al., 2010).

The presented study was conducted on T. hermanni and A. horsfieldii. Both species belong to herbivores. In their natural habitat, Hermann's tortoises (Testudo hermanni) inhabit rocky grass-covered areas with high sunlight exposure. Their natural habitat covers the area of the Mediterranean Basin. Hermann's tortoises are active in spring, summer and autumn, while they hibernate in winter. The peak of their circadian activity is the morning and the late afternoon. While the Central-Asian tortoises (Agrionemys horsfieldii) inhabit dry rocky grass-covered areas. They are active in spring, and may hibernate for as long as nine months in a year. In their natural habitat, plant food is available for approx. 3 months only, which is the reason why their life cycle is heavily dependent on the vegetation season. Central-Asian 
tortoises are active for approximately 7 hours a day. Their diet is rich in fibre, but poor in protein (Bergmann, 2001). The naturally occurring populations are becoming extinct due to mass-scale harvesting of this species (Stubbs, 1989).

The nomadic lifestyle of these tortoise species and their opportunistic feeding habits may substantiate a thesis that the novelty of the stimulus plays a significant regulatory role in shaping the behaviour of these animals. As the importance of sight in regulating their behaviour is well-documented (Pellitteri-Rosa et al., 2010), the experiments described below involved the use of visual stimuli.

The purpose of our study was to investigate the responses of land tortoises to new objects which appeared in their immediate environment.

\section{Method}

\subsection{Animals Studied}

Study subjects were three experimentally naive tortoises: two of the Testudo hermanni species (females) and one of the Agrionemys horsfieldii species (male). At the start of the experiment, the Testudo hermanni tortoises were approx. 15 and 13 years old. The Agrionemys horsfieldii was approx. 14 years old. Prior to the experiment, they dwelled in pens $(77 \times 70 \times 20 \mathrm{~cm})$ : the Testudo hermanni communally in one pen, and the Agrionemys horsfieldii solitarily in another pen. The tortoises had constant access to water. For 12 hours a day they were exposed to an additional heat source - a standard 60 WATT light bulb placed in the corner of each of the pens. The temperature inside the pens was approx. 23 degrees Celsius, and the humidity level was maintained at approx. 50\%. All of the tortoises participating in the experiment had been hibernating for a period of 5 months, during the winter time (November-March). The experiment was conducted in the course of July and August.

\subsection{Research Apparatus}

The study space comprised an experimental arena surrounded with a 80 -cm-tall screen to prevent the animals from looking at any objects outside of the arena (see Fig. 1). A dome-shaped box (30 $\mathrm{cm}$ in diameter, $11 \mathrm{~cm}$ in height) with three symmetrically distributed openings ( $2.4 \mathrm{~cm}$ in diameter) was placed in the middle of the arena. The size of the openings made it possible for the tortoises to stick their heads out of the openings without encountering any physical barrier. Three open tunnels $(15 \mathrm{~cm}$ wide, $15 \mathrm{~cm}$ high and $30 \mathrm{~cm}$ long) were fixed at the level of the openings. The dome-shaped box was placed in the same position during each study session and it was immobilised by means of an additional weight to avoid displacement during the experiment. 


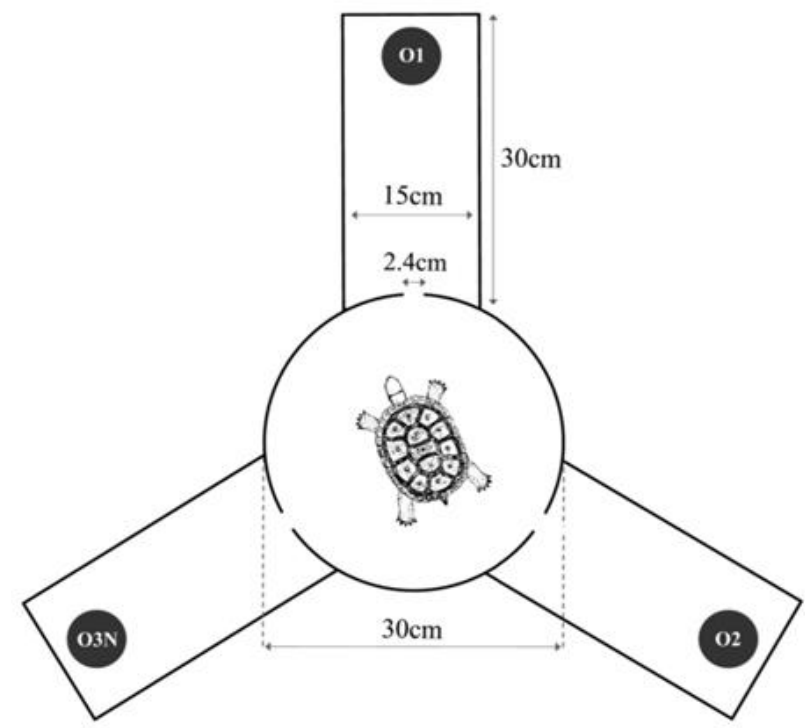

Fig. 1. An outline of the experimental arena. O1 - biologically significant object, $\mathrm{O} 2$ biologically insignificant object, $\mathrm{O} 3 \mathrm{~N}$ - stimulus variable between sessions.

The objects $(\mathrm{O} 1, \mathrm{O} 2, \mathrm{O} 3 \mathrm{~N})$ were placed at the end of the tunnels - their configuration was altered from one day to the next on a random basis. One of the objects was an item imitating a green plant $(\mathrm{O} 1)$ - see Fig. 2. The underlying assumption was that the tortoises would respond strongly to an object resembling their typical food. The second constant object was a yellow sphere, $10 \mathrm{~cm}$ in diameter $(\mathrm{O} 2)-$ see Fig. 2. The third object $(\mathrm{O} 3 \mathrm{~N})$ presented to the tortoises varied from one study session to the next over the course of the experiment. The variable objects were of different shapes and colours, yet did not diverge greatly from the constant objects in these respects - they were $5-10 \mathrm{~cm}$ wide and maximum of $10 \mathrm{~cm}$ high.
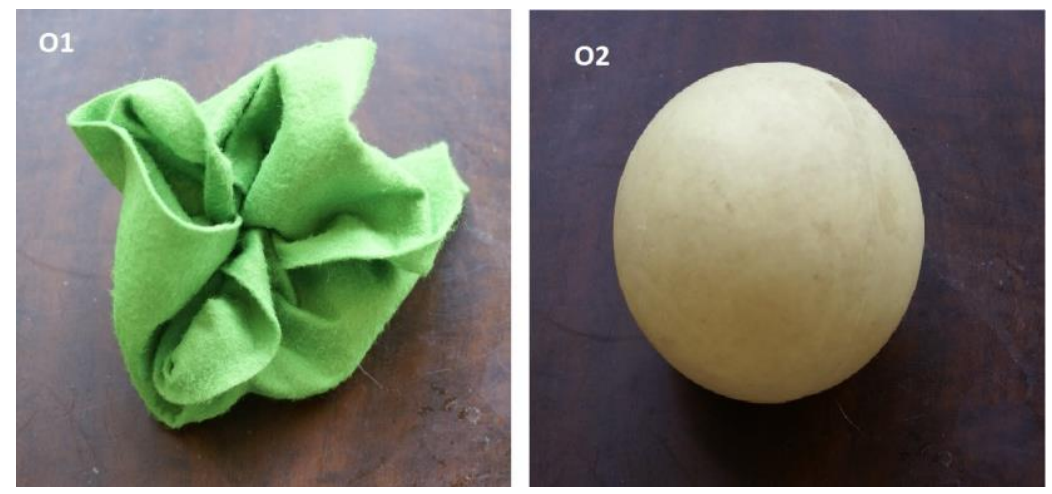

Fig. 2. Constant objects/stimuli used in the study.

The variable objects were the following (in the order in which they were presented): nail clippers, a cardboard matchbox, a car model, a pink nail polish, a small furry toy, a claret-coloured candle, a roll of sticky tape, a white porcelain glass, a measure tape, an empty grey toilet paper roll, a white mug, a white plug-in time switch, a "pepsi" glass, a small elephant figure, a pill box, a dark-blue and white light-bulb box, a grey furry toy rat, a roll of 
white toilet paper, a white nailbrush, a small green plant in a pot, a pink highlighter, a bright-green cardboard box, a small jar filled with coffee, a 0.5 litre water bottle, a paper ball, a beige mug, a pill box, a blue pen, a small white plastic bowl, and an orange watering can cork.

\subsection{Procedure}

The duration of the study was 40 days divided into cycles of 5 days of study and 2 days of interlude. The tortoises were always studied in the same order and at the same time of day. They were fed green vegetables 5 times a week after the end of each study session. The observations were carried out during the day, in the morning, which coincided with the peak of tortoises' circadian activity in their natural habitat.

Each of the tortoises was taken out of their pens, transported to the research apparatus, placed under the dome (in a randomly selected direction), from where it could look a the objects presented through the openings in the dome. Measurements were taken of the time and frequency with which it stuck its head out in the direction of particular objects. The length of each observation session was 50 minutes for each of the tortoises. After the session, a given tortoise was put back in the pen, and the experimental space was rinsed with water.

A video camera was fixed above the experimental space to record the behaviour of the animals.

\section{Results}

Given the preliminary, exploratory nature of the study, the statistical procedures which were employed provide no accurate basis for testing directional hypotheses (see also Valentine, Aloe and Lau, 2015). However, in order to better illustrate the preliminary results obtained, Repeated Measures ANOVA (within subject design) was used for each of the individuals separately. Three dependent measurements (behavioural measures embedded in the stimulus object) were applied in the analysis with respect to each tortoise in the study, with each measurement session constituting a separate data record. The descriptive statistical data is presented in Table 1; the ANOVA results are shown in Table 2.

Table 1. Descriptive statistics of the measures taken in the study. Occurrence - total number of staring responses; Duration - total time spent on staring responses.

\begin{tabular}{|l|c|c|c|c|c|}
\hline \multicolumn{7}{|c|}{ Tortoise \#1 } \\
\hline \multicolumn{1}{|c|}{ Attribute } & Min & Max & Average & Std-dev & Std-dev/avg \\
\hline O1-occurrence & 0 & 39 & 12.4 & 9.95 & 0.80 \\
\hline O2-occurrence & 0 & 12 & 3.83 & 3.68 & 0.96 \\
\hline O3-occurrence & 0 & 29 & 7.43 & 6.54 & 0.88 \\
\hline O1-duration & 0 & 1200 & 355.67 & 332.75 & 0.94 \\
\hline O2-duration & 0 & 502 & 85.53 & 121.94 & 1.43 \\
\hline O3-duration & 0 & 443 & 152.1 & 128.18 & 0.84 \\
\hline
\end{tabular}




\begin{tabular}{|l|c|c|c|c|c|}
\hline \multicolumn{7}{|c|}{ Tortoise \#2 } \\
\hline O1-occurrence & 0 & 102 & 26.46 & 30.22 & 1.14 \\
\hline O2-occurrence & 0 & 65 & 16.14 & 20.64 & 1.28 \\
\hline O3-occurrence & 0 & 101 & 20.34 & 24.41 & 1.20 \\
\hline O1-duration & 0 & 2240 & 308.31 & 464.30 & 1.51 \\
\hline O2-duration & 0 & 575 & 109.57 & 161.27 & 1.47 \\
\hline O3-duration & 0 & 1035 & 220.34 & 299.14 & 1.36 \\
\hline \multicolumn{7}{|c|}{ Tortoise \#3 } \\
\hline O1-occurrence & 0 & 19 & 6.07 & 5.08 & 0.88 \\
\hline O2-occurrence & 1 & 18 & 4.63 & 4.00 & 0.86 \\
\hline O3-occurrence & 0 & 13 & 5.67 & 3.34 & 0.59 \\
\hline O1-duration & 0 & 96 & 19.26 & 24.64 & 1.28 \\
\hline O2-duration & 1 & 54 & 10.03 & 11.46 & 1.14 \\
\hline O3-duration & 0 & 84 & 22.07 & 22.37 & 1.01 \\
\hline
\end{tabular}

Table 2. Repeated Measures ANOVA across stimulus objects of the variables taken in the study, for each subject independently.

\begin{tabular}{|l|c|c|}
\hline & Number of staring responses & Duration of staring \\
\hline Tortoise \#1 & $\mathrm{F}(2,89)=12.46, \mathrm{p}<0.001$ & $\mathrm{~F}(2,89)=10.86, \mathrm{p}<0.001$ \\
\hline Tortoise \#2 & n.s. & n.s. \\
\hline Tortoise \#3 & n.s. & $\mathrm{F}(2,89)=2.79, \mathrm{p}=0.069$ \\
\hline
\end{tabular}

\section{Discussion}

The results obtained indicate the presence of a constant pattern in all three individuals studied. The sphere $(\mathrm{O} 2)$ elicited the smallest number of responses involving looking intently at the object, while the plant-like $(\mathrm{O} 1)$ and the variable objects $(\mathrm{O} 3 \mathrm{~N})$ elicited such a response to a far greater degree. In the case of all individuals, there was high variability in measurements of specific responses in the subsequent measurement sessions. Nevertheless, the following conclusions may be drawn on the basis of the above-described preliminary study:

- the tortoises show an exploratory response which varies due to the object being studied,

- the stimulus which imitates a biologically significant object elicited more and longer-lasting responses in tortoises which involved the animals' looking intently at the object,

- the variable stimuli elicited more and longer-lasting responses in tortoises which involved the animals' looking intently at the object, as compared with the responses to the constant biologically indifferent stimulus.

It may be suggested, therefore, that land tortoises from the Mediterranean Basin (Testudo hermanni) and Central-Asian tortoises (Agrionemys horsfieldii) may constitute interesting study subjects in comparative psychology, in studies aiming to examine the evolution of 
cognitive processes in amniotes.

\section{Acknowledgement}

This study was funded by the research project of The National Science Centre \#UMO-2013/09/B/HS6/03435.

\section{References}

Broglio, C., Martín-Monzón, I., Ocaña, F. M., Gómez, a., Durán, E., Salas, C., \& Rodríguez, F. (2015). Hippocampal Pallium and Map-Like Memories through Vertebrate Evolution. Journal of Behavioral and Brain Science, 05(03), 109-120. http://dx.doi.org/10.4236/jbbs.2015.53011

Bergmann, P. (2001), The natural history of the Central Asian Tortoise. The Newsletter of the Colorado Herpetological Society, vol. 28, No.10.

Pellitteri-Rosa, D., Sacchi, R., Galeotti, P., Marchesi, M., \& Fasola, M. (2010). Do Hermann's tortoises ( Testudo hermanni ) discriminate colours? An experiment with natural and artificial stimuli. Italian Journal of Zoology, 77(4), 481-491. http://dx.doi.org/10.1080/11250000903464067

Pisula, W. (2009). Curiosity and Information Seeking in Animal and Human Behavior (first edit). Boca Raton: BrownWalker Press.

Salas, C., Broglio, C., \& Rodríguez, F. (2003). Evolution of Forebrain and Spatial Cognition in Vertebrates: Conservation across Diversity. Brain, Behavior and Evolution, 62(2), 72-82. http://dx.doi.org/10.1159/000072438

Tinklepaugh, O. L. (1932). Maze learning of a turtle. Journal of Comparative Psychology, 13(2), 201-206. http://dx.doi.org/10.1037/h0071489

Valentine, J. C., Aloe, A. M., \& Lau, T. S. (2015). Life After NHST: How to Describe Your Data Without “p -ing” Everywhere. Basic and Applied Social Psychology, 37(5), 260-273. http://dx.doi.org/10.1080/01973533.2015.1060240

\section{Copyright Disclaimer}

Copyright for this article is retained by the author(s), with first publication rights granted to the journal.

This is an open-access article distributed under the terms and conditions of the Creative Commons Attribution license (http://creativecommons.org/licenses/by/3.0/). 